\title{
Confronting Asian Concerns in Engaging Learners

\author{
to Online Education
}

\author{
Ganakumaran Subramaniam \\ Universiti Kebangsaan Malaysia \\ 43600 Bangi, Selangor \\ Tel: 60-3-8921-4187 E-mail: gana@ukm.my
}

\begin{abstract}
Researchers have theorized that cultural emphasis on education plays a major role in explaining Asian students' achievement. While Asian parents often view education as the main vehicle for upward social mobility, the social and cultural make-up of Asian societies and the context within which education is conducted in Asia often clash with the modern approaches and methodologies adopted into Asian classrooms. Contemporary approaches to education especially in relation to autonomous, learner-centred and online philosophies though theoretically supported and statistically proven successful in the west have been slow to capture Asian learners' interest and engagement. This paper discusses some of the reasons for the problems and challenges that need to be confronted prior to the introduction and effective implementation of autonomous online learning programmes. It further describes an attempt at confronting the above issues through a research project conducted by group of academics from the National University of Malaysia. The paper concludes by featuring some of the principles and strategies employed in the online programme developed for the research and the implication of their use on learner engagement to online autonomous learning programmes.
\end{abstract}

Keywords: Online learning, Learner autonomy, Online learning methodologies, Learner strategies, Learner preferences

\section{Introduction}

Education is becoming more and more a global phenomenon with nations and cultures attempting to keep up in the race to establish economic competitiveness in a world that continues to become borderless. Such competitiveness is mirrored in education by attempts to implement and enforce philosophies, theories, methods and practices that have been deemed have borne results in economically progressive and successful societies.

Forestier (1998:23) quoted these words of a South Korean business leader to echo the above sentiments:

The extent of the country's economic difficulties has highlighted the inadequacies of South Korean education. There is a need for a completely new type of schooling which is capable of producing the original thinkers, entrepreneurs and self-starters the country needs.

Even more evident is the push to learn the languages of the these successful societies not only because fruitful economic ventures may be drawn from them but also because these languages like English were the mediums in which current and cutting-edge knowledge is embodied.

The twentieth century witnessed drastic changes to age old traditions of the sage-disciple paradigm in the classroom. The period saw the development many new and innovative teaching-learning methodologies and environments. The age of the computer made the most significant impact with the incorporation of computer assisted and computer mediated methodologies. The birth of the World Wide Web further enhanced the use of computer technology in education and opened up avenues for its use in a multitude of ways transcending national borders.

In the western world very few people have escaped the incursion of technology into everyday life. In stating that technology has changed not only the work place, but also the classroom, Heeger (2002) illustrates the following statistics in support of the growing online education practices in the United States and Europe.

- The International Data Corporation estimates that about 2 million students took online courses from U.S. higher education institutions in 2002. By 2006, there will be 5 million - or more!

- A growing number of colleges and universities are offering fully online courses or degrees as well as web-based services to students. Almost all institutions include at least some web-enhanced or hybrid courses in their curriculum. 
- Corporate spending on e-learning is expected to quadruple to $\$ 18$ billion in the next three years. Just-in-time virtual training reaches employees of American businesses and corporations worldwide.

- The European Union has established a \$13.3 billion “eLearning Action Plan;" Universitas 21, a multinational online consortium focused on Asian students, plans expansion to Africa and Latin America; and numerous Internet-based distance learning institutions are springing up from Tunisia to Sweden and from Indonesia to Uzbekistan.

\section{The Asian Learner and Online Learning Methodologies}

The reaction of Asian students to approaches that are new and western in their orientation can only be understood upon gaining an understanding of the general characteristics of Asian students. Asian cultural and socialization characteristics are of primary interest here. An examination of researched generalizations in Asian learners' cultural and socialization make-up against the primary constructs online learning methodologies helps highlight some of the anomalies.

Cultural and socialization practices identified are supported by finding from a research conducted by Littlewood (1999) in Hong Kong. Refer to Table 1 in the appendix for details. This research indicates that majority of Asian students:

- Like working in groups

- Attempt to maintain a sense of harmony

- Are hesitant to stand out as individuals

- Rely on teachers to impart knowledge

- Expect teachers to evaluate their learning

- Match success to the meeting of family and social group goals

Rao (2001:2) further elaborates that:

The teacher-centered classroom teaching in East Asia also leads to a closure-oriented style for most East Asian students. These closure-oriented students dislike ambiguity, uncertainty or fuzziness. To avoid these, they will sometimes jump to hasty conclusions about grammar rules or reading themes. Many Asian students, according to Sue and Kirk (1972), are less autonomous, more dependent on authority figures and more obedient and conforming to rules and deadlines.

Based on the above positions a national level research was conducted on Malaysian undergraduates in an attempt to locate solutions for online and autonomous learning challenges confronting Asian education.

\section{The Malaysian Problem and Attempts at Solutions}

The use of online autonomous learning programmes has often been associated with proficiency-type courses. In Malaysia the teaching of content courses using the online mode is at infancy stages. Traditionally the education system in Malaysia has not provided much room for learner autonomy. The culture and tradition of the people too has not encouraged independence and autonomy among students. As such students are overly teacher dependent and have to be spoon fed with information. Even though attempts have been made by the Ministry of Education over the years to wean students away from total teacher dependence and towards greater self-reliance and peer dependence it has not been very fruitful. As a result even at tertiary levels students have not acquired autonomy and independence as revealed by Thang (2001).

\section{Profile of the Malaysian Student}

The hypothesized that in order to prepare online material that would be most effective and attractive to a wide range of students, the material designers should have a detailed profile of the kind of students who would be subscribing to the course. The profiling would include the social, educational and economic backgrounds of the student, their learning habits, learning styles preferences and so on. The profiling of the literature student for this research was done with the aid of a questionnaire consisting of 82 questions, adapted from the Munby model (1978). It was piloted at National University of Malaysia before it was distributed nationwide.

The data collected through the questionnaire was analyzed using the SPSS software and provided wide range of information. For the purpose of this paper only selected information is used to profile Malaysian student.

In attempting to categorize the students according to learning styles, the data revealed that the respondents were equally distributed into the different learning styles such as inductive reflective intuitive deductive, electronic, and autonomous learning. This could be due to the fact that the literature students appropriate different learning styles for different purposes and normally do not subscribe to one or two particular learning styles. Informal interviews with some of the respondents confirmed this for a fact.

\subsection{Race}

The study also wanted to investigate whether there were any particular patterns in terms of race in categorizing the students according to learning styles. The results were: 


\section{Malay Undergraduates}

The analysis shows that a significant numbers of Malay students are inductive, reflective and intuitive learners. There is no significant numbers for deductive learners among Malay students.

Malay students also show significant preference for classroom learning.

However this is contrasted with findings that suggest a significant number also preference for autonomous learning. An explanation for this may be that in practice the Malay students are comfortable and confident in the traditional classroom but they realize the importance of independence and autonomy in all aspects of life as envisaged by the community leaders.

All Malay respondents show a significant correlation between learning styles, and electronic learning, teacher-centered learning, classroom learning, autonomous learning and individual learning.

\section{Chinese Undergraduates}

The analysis shows that the Chinese learners cut across all four learning styles grouping.

Chinese learners show significant preference for teacher-centered learning, classroom learning and individualized learning. This again could be attributed to their culture and social values which stresses on communal strength and working in groups. However, as students at tertiary level they are also aware of the importance of being independent and self-directed.

It is also interesting to note that Chinese deductive learners show the greatest correlated significantly towards autonomous and individualized learning, where else Chinese inductive learners show a correlation for classroom learning. This finding correlates with literature that suggests that inductive learners prefer and need more formal theoretical and conceptual input for learning to take place. In contrast, deductive learners are more comfortable in informal and self-directed learning situations.

\section{Indian Undergraduates}

The analysis shows significant numbers of Indian students as being inductive, reflective and intuitive learners. There is no significant number for deductive learning for Indian students.

Indian students generally show a greater correlation between learning styles and teacher centered learning, classroom learning, autonomous learning and individualized learning.

Indian reflective learners show no significant correlation to any of the variables.

Indians show a greater tendency (significance) for reflective learning in comparison to Chinese learners. This finding suggests that Indian undergraduates seem to require greater time on task for effective learning to take place through reflection and conceptualization. Hence, the online programme would work ideally with such students provided they are systematic and disciplined in working through the programme.

\section{Bumiputra Undergraduates}

The analysis shows significant numbers of Bumiputra (Bumiputra students are the members of native ethnic groups of Malaysia) students are inductive, deductive and intuitive learners. There is no significance for reflective learning for Bumiputra students.

Bumiputra learners show significance in correlations between learning styles and teacher-centered learning as well as autonomous learning

Bumiputra students also show greater significance for electronic learning compared to Indian students. This surprising finding has been ascertained through interviews to Bumiputra belief that they need to work extra hard to succeed with their challenging environment. Many Bumiputra students in universities have also had the opportunity to spend their secondary education years in boarding schools or matriculation centers.

\subsection{Gender}

\section{Male}

The data shows male students are significantly distributed across inductive, reflective and intuitive learning styles groupings.

Male's students show a greater correlation to reflective learning styles.

They also show a significant preference for classroom learning, autonomous learning and individualized learning.

$\underline{\text { Female }}$

Female learners show significant distribution across all four learning styles. They also show significant correlation between learning styles and electronic learning, teacher centered learning, classroom learning, autonomous learning and individualized learning. 
Female students show a greater correlation to intuitive learning.

\section{General conclusions:}

Both genders show greater significant preference to teacher centered learning compared to electronic learning and classroom learning.

This generally suggests that Malaysian learners prefer linear, systematic and progressively organized and developed learning patterns.

\subsection{Computer Usage}

The general pattern of computer usage among all learners is between 5-9 hours per week. This is due to the fact that most students still rely very heavily on the faculty's computer labs to do most of their work. They also find that it is extremely expensive to use the cybercafés at their halls of residence. As for those who own their computers, they are unable to connect to the internet as there is no LAN or WAN facilities in their rooms.

Only $17 \%$ of the total populous seems to be spending more than 20 hours per week in front of the computer and these are students who travel from home or those staying outside campus.

A significant number of students (more than $30 \%$ ) spend less than $5 \mathrm{hrs}$ a week working with computers. These are students who either are not computer savvy or cannot afford the high cost of cybercafés.

As with other studies (e.g. Biggs 1994), this research also identified three general categories of learners: Participant learners, Achievement learners, and the Knowledge learners. Table 2 in the appendix below describes each kind.

Based on the above learner profile and their associative needs, a team of researchers, Ruzy, Thang, Ganakumaran.S., and Nackeeran S. funded by an IRPA (Intensified Research in Priority Area) grant embarked on a project to develop an online programme, for the undergraduate students of Bachelor of Arts of English Language Studies (B.A.ELS). The focus of this paper will be findings from the online programme for the B.A ELS students. This online programme demands the students to register themselves with the Learning Care Platform to have access to the online notes, resources and exercises. The purpose of this programme is to provide further information, resources and assistance to help students have a better understanding of the literary texts and theories. The programme is also designed to develop students' autonomy, awareness and motivation in analyzing various genres of writing. This online programme worked in tendem with normal face to face class teaching.

There may be many reasons for the wide spread apprehension and resistance towards online autonomous study among Malaysian learners. Research has identified amongst others the following reasons

\section{Fundamental Skill and Psycho-social Deficiencies}

Within this category are subsumed basic computer (PC) and typing skills. Good typing skills help learners access information and to key in entries fast in text chat sections. Learner training on the goals and expectations of online programmes is also vital to ensure that socialization problems do not occur. Many learners find it difficult and lonely working by themselves on tasks and educational objectives delivered through computer screens. They find the challenge of fending for themselves and being responsible for their own learning without a readily available teacher, daunting. In addition Malaysian students often rely on group support for learning in understanding new concepts and language forms which is absent in online programmes.

\section{Re-orientation Challenge}

Most online programmes are designed targeting total learner autonomy. This means that students can and may work alone and at their own pace. One challenge that this model poses is that it often totally contradicts conventional classroom teaching methodologies which encourage social learning approaches through cooperative and collaborative learning. Students, who have over the years become accustomed to such learning environments, find it challenging to adapt to online programme expectations, implementation and goals. Furthermore, the conventional online autonomous learning programme often is also often in conflict with learning styles and intelligences that are interpersonal.

\section{Motivation Deficiencies}

Therefore it is not surprising that the greatest challenge to online autonomous learning is not as much the technology or the subject matter but learner motivation for sustained participation in online learning. Harasim et al. (1995) believes that the most important characteristic for students' success in this mode of learning is motivation. Much of the reasons for the lack of motivation have already been discussed in the sections above and are related to lack of competencies, literacies and conflicts of culture and with personal learning styles and intelligences.

\section{Responses to Learning and Feedback Deficiencies}

Giving immediate feedback and responses to learner tasks and contributions has always been strongly advocated in conventional classroom settings. This enables learners to be corrected or to self-correct and progress smoothly along the 
learning continuum. Online learning programmes which propagate independence from traditional boundaries of teaching-learning time and space may be unable to meet the learners' needs for immediate responses or feedback to their work. Delayed feedback leads to frustration and loss of motivation because learners are unable to proceed along their respective learning curves.

This research project explored several ways to sustain learner interest and participation on the literature online programme. The risk that learners would remain in the comfort zones because of the availability of face-to-face teaching was a fear. Hence the online programme was designed with continuum of learning experiences in mind which would lead learners through controlled participation to totally free engagement with literary material in the Learning Care Platform.

The illustration in Diagram 1 below shows how the literature online programme is tailored in such a way that at initial stages learners have little option but to engage with the Learning Care Platform. This situation is created in the following modes:

\section{Lecture Notes}

In the early weeks of the course (weeks 1-5) learners are introduced to topics through face-to-face lectures following which lecture notes are placed in the Learning Care Platform. Consequently, learners are asked to log on and download the notes they require. Malaysian students having been totally reliant on notes and hand-outs from their teachers never fail to do the expected. As the weeks progress, certain topics are not covered through face-to-face teaching and notes related to the topics are however placed on the platform. Learners are required to read these notes before participating in small group tutorials with the course instructor.

\section{Supplementary Guidance and Notes}

Apart from lecture notes the platform also contains supplementary material that may be used by learners to better understand the language text, elements or issues featured in the course. Though it is not compulsory or a necessary for students to access and use these note, majority of the students do for simple fact that they do not want to lose out on valuable information available to other course members.

\section{Guided Learning Activities}

The aspect of the Learning Care focuses on helping learners work out and interpret language texts through a systematic series of progressively designed learning activities. The focus of these activities is learning and helping learners develop language skills and competencies necessary to succeed in the course. It is noted that many students prefer to attempt these learning activities rather than be reliant on course mates or instructors who work to time. It is only in instances when these activities fail to help that they venture to seek the instructor's assistance. Often these activities are designed to prepare learners for course assessments.

\section{Course Assessment based Self-Assessment}

This section on self-assessment contains activities that cover the skills and competencies that are addressed in the actual course assessment. Learners are informed of this feature at the beginning of the course. Self-assessment activities are varied and cover all topics offered in the course. Learners never fail to engage in these activities as they understand the value the practice may offer to their eventual performance in course exams. This section works well with Malaysian students who have all along been focused on examination performance and achievement. Students who are not examination oriented tend to visit this section in last minute efforts to prepare for exams.

In the sections on guided learning activities and course assessment-based self assessment the researches utilized activities developed based on Elbaum, Havvind \& Tinker's (2000:143) five full-spectrum questions:

- Questions that probe the "so what!" response- relevance, interest level, urgency and context

- Questions that clarify meaning or conceptual vocabulary- ambiguity or vagueness and common concepts

- Questions that explore assumptions, sources and rationale- qualities assumed and study evidence

- Questions that seek to identify causes and effects or outcomes-primary

- or secondary and causes, internal or external factors

- Questions that consider appropriate action- weigh different courses of action

\section{Blogging}

Blogging or chatting with a specific purpose on a fixed topic is another feature of the Learning Care Platform. The course instructor normally initiates discussion topics based pertinent areas/texts in the course. Learners are told that their participation is monitored and may feature in the award of $10 \%$ of the course marks set aside for class participation. After an initial period of apprehension and lack of confidence learners begin engaging in the blogging activity. Slowly the activity takes life and many students begin participating enthusiastically. The instructor simply plays the role of a 
moderator and can participate either as himself or using a pseudonym. Ultimately many students find a liberating and enriching experience as they do not have to content with matters related to "face", language limitations and competence.

Complementing all the above techniques and strategies is the platforms capacity for interactivity and multimedia support. Initial interests in most students are drawn towards sophisticated but useful multimedia elements that support their learning.

The Learning Care discussions take learners beyond the context of one literary text, creating hypothetical situations for intertextual engagement. In the above example a problem situation is created through simulation where a female character each from a different novel/short story is engaged in a discussion of their positions and challenges in their respective communities. Such activities not only require learners to be critical and analytical but also creative in working out the possible discourses that traverse between the characters.

Correlation between learner participation in the Learning Care environment and the students learning style preferences and personality explain why some students feel comfortable working on online programmes almost immediately, whereas others slow to warm-up to such learning environments. Data at initial stages of the programme suggests that only a small number of students showed clear preference for online learning. The apprehension in the majority indicated a preference for face-to-face classes and real-time discussion.

On the other hand, students whose profile described them as shy or introverted and had difficulty participating in face-to-face classroom interaction found the online environment liberating as it allowed them the luxury of time to plan and contribute, without the competition from more vocal students. As the online programme was time-independent it allowed learners to be reflective, critical and creative, and compose thoughtful rather than spontaneous responses. These features endowed the learning environment with a democratising atmosphere.

The data also highlighted two types of participation in the blogging activity. Henri $(1989,1992)$ categories such messages as independent and interactive messages. Independent messages deal with the topic of discussion, but make no implicit or explicit reference to any other messages. Interactive messages deal with the topic, but also refer to other messages by responding to them, elaborating on them, or building on them in some fashion. At initial periods of the blogging activity most messages were independent, i.e. addressing only the topic of discussion or discussion question. However, as learners became bolder and confident about their ability to make sense regarding the topic they began to engage with comments made by other learners regarding the topic.

Comments made by students at the end of the course regarding the value of the online programme has been organized and listed below according importance.

Enables the enrichment of knowledge and better understanding of language use

- Provides viable opportunities to exchange ideas with others

- Offers opportunities express own views without fear of failure

- Allows opportunities to creatively engage in the communicative process

- Creates opportunities to read other points of view and comment on them

- Improves critical and creative thinking

- Improves skills of writing

- Allows for whole-class participation

\section{Conclusion}

Primarily the success of an online course or program is impacted by the readiness of the students to embrace this method of delivery. Students must have the necessary technological knowledge and skills available to them in addition to access to suitable hardware, software and Internet access before they can benefit from this type of program. Furthermore students must be self-directed learners and responsible for their own learning. They may also be frustrated by technical delays through server breakdowns or loss of internet connections. Culture may also affect the success of online courses or programs. It has been found that even some Asian students, whose command of the English language is reasonably good, are reluctant to participate in the online discussions and collaborative assignments.

A major adult education goal is helping students become independent learners with the ability to monitor and improve their thinking skills. Courses and programmes that integrate online courseware need to integrate meaningful instructional activities that promote internalization of critical and creative thinking skills and knowledge. This study concludes that although the technology may have attributes that have the potential to create a dynamic and interactive educational experience, it requires more than technology to create effective and enriching learning experiences. Other factors that have significant influence include student characteristics, their learning preferences, their cognitive maturity, 
and their ability to participate in interaction, and critical thinking. The results of this study support the view of Harasim et al. (1995) and others that these attributes must be exploited by using appropriate design and facilitation techniques.

\section{References}

Carnall. C. (2003). Managing Change in Organisations. Prentice Hall: Harlow.

Chapelle, Carol A. (2001). Computer Applications in Second Language Acquisition: Foundation for Teaching, Testing and Research. Cambridge: Cambridge University Press.

Forestier, K. (1998) Asian crisis spurs lesson in learning. South China Morning Post August 11, p. 15.

Garrison, D. R. \& terry Anderson. (2003). E-Learning in the $21^{\text {st }}$ Century: A Framework for Research and Practice. London: RoutledgeFalmer.

Grabe, Mark and Cindy Grabe. (2004). Integrating Technology for Meaningful Learning. Boston: Houghton Mifflin Company.

Harasim, L. (1990). On-line education: An environment for collaboration and intellectual amplification. In L. Harasim (Ed.), On-line education: Perspectives on a new environment (pp. 39-64). New York: Praeger.

Harasim, L. (1991). Researching online education: Perspectives and methodologies. Paper presented at the American Educational Research Association conference, Chicago.

Heeger, G.A. (2002). Building the Online Learning Enterprise. The Virtual University: Academic and Corporate Conference. Institutes for Professional Development. Teachers College, Columbia University. Monday, June 24, 2002.

Henri, F. (1989). La téléconférence assisté par ordinateur dans une activité de formation à distance. Unpublished doctoral dissertation, Concordia University.

Henri, F. (1992). Formation a distance et téléconférence assistée par ordinateur: Interactivité, quasi interactivité, ou monologue? Journal of Distance Education, 7(1), 5-24.

Henri, F. \& Kaye, A. (1993). Problems of distance education. In K. Harry, J. Magnus, \& D. Keegan (Eds.). Distance education: New perspectives (pp. 25-32). New York: Routledge.

Ibrahim Ahmad Bajunid. (2001). "The Transformation of Malaysian Society through Technological Advantage: ICT and Education in Malaysia". Journal of Southeast Asian Education. 2 (1): 104-146.

Jochems, Wim, Jeroen van Merrienboer \& Rob Koper. (2004). Integrated E-Learning: Implications for Pedagogy, Technology and Organization. London: RoutledgeFalmer.

Leigh, A \& Walters. M. (1998). Effective Change: Twenty Ways to Make It Happen. Institute of Personnel and Development, London.

Levy, Michael. (1997). Computer-Assisted Language Learning: Context and Conceptualization. Oxford: Oxford University Press.

Littlewood, W. (1999). Questioning Some Assumptions about South Asian Students. Applied Linguistics.

Mohd Sallehuddin Abdul Aziz \& Ruzy Suliza Hashim. (2003). "Learners' Self-Assessment of Language Skills." Language and Nationhood Conference Proceedings. 16-18 ${ }^{\text {th }}$ December 2003. (In cd)

O' Sullivan, Edmund. (1999). Transformative Learning: Educational Vision for the $21^{s}$ Century. Toronto: Zed Books.

Plant, R. (1995). Managing Change and Making it stick. Harper Collins: London.

Mason, R. (1989). A case study of the use of computer conferencing at the Open University. Unpublished doctoral dissertation, UK Open University.

Mason, R. (1991). Analyzing computer conferencing interactions. International Journal of Computers in Adult Education and Training, 2/3, 161-173.

Mason, R. (1998). Models of online courses. ALN Magazine, 2(2). http://www.aln.org/alnweb/magazine/vol2_issue2/Masonfinal.html

Mason, R., \& Kaye, T. (1990). Toward a new paradigm for distance education. In L. Harasim (Ed.), Online education: Perspectives on a new environment (pp. 15-38). New York: Praeger.

Nunan, David. The Learner-Centred Curriculum: A Study in Second Langange Teaching. Cambridge: Cambridge University Press.

Rao Zhenhui Matching Teaching Styles with Learning Styles in East Asian Contexts. The Internet TESL Journal, Vol. VII, No. (July 7, 2001) 
Ruzy Suliza Hashim et. Al. (2003). “Tinjauan terhadap ciri-ciri pelajar bagi mengenalpasti kesediaan pelajar untuk pembelajaran atas talian bagi sastera dalam Bahasa Inggeris.” Prosiding Seminar IRPA RMK-8 2003. Bangi:UKM. ms 251-254.

Sadagopan, Fiona Lalitha. (2004). "An Analysis of Student Preferences for Online Learning of Literature at Undergraduate Level in Universiti Kebangsaan Malaysia”. Unpublished MA Thesis.

Scharle, Agota \& Anita Szabo, (2000). Learner Autonomy: A Guide to Developing Learner Responsibility. Cambridge: Cambridge University Press.

Shulman, L.S. (1988). Disciplines of inquiry in education: An overview. In R.M. Jaeger (Ed.), Complementary methods for research in education (pp. 3-19). Washington, DC: American Educational Research Association.

Silvia Bartolic-Zlomislic \& A.W. (Tony) Bates. (2005). Investing in Online Learning: Potential Benefits and Limitations. The University of British Columbia. bates.cstudies.ubc.ca/investing.html. (20 Sept 2005).

Stuart, N. (1997). "The Policy of UK Government on Lifelong Learning”, in Coffield, F. (ed.) A National Strategy for Lifelong Learning. Newcastle: University of Newcastle.

Table 1. Cultural and Socialization Practices

\begin{tabular}{|l|ll|}
\hline Asian Cultural and Socialization Practices & Online Learning Methodologies \\
\hline $\begin{array}{l}\text { Asian culture is more conservative and } \\
\text { constrained }\end{array}$ & $\begin{array}{l}\text { Requires aggressive and independent } \\
\text { engagements }\end{array}$ \\
\hline Allegiance to native language & $\begin{array}{l}\text { Mostly requires English or other European } \\
\text { languages }\end{array}$ \\
\hline $\begin{array}{l}\text { Group consciousness - cooperative and } \\
\text { collaborative learning culture }\end{array}$ & $\begin{array}{l}\text { Individual and independent learning } \\
\text { responsibilities }\end{array}$ \\
\hline "Sibling" learning support system - mentorship & Personalized learning and learning assessment \\
\hline Authority directed learning - fixed curriculum & Self-directed learning - flexible curriculum \\
\hline Teacher sage and fountain of knowledge & $\begin{array}{l}\text { Autonomous learning guided by learning } \\
\text { programmes }\end{array}$ \\
\hline
\end{tabular}

Table 2. General Categories of Learners

\begin{tabular}{|l|l|l|}
\hline Type of learner & Motivation & Strategies \\
\hline $\begin{array}{l}\text { Participant } \\
\text { Achievement Learner }\end{array}$ & $\begin{array}{l}\text { Wust wants to pass } \\
\text { grades }\end{array}$ & $\begin{array}{l}\text { Focuses on surface meaning. Does the minimum amount of study and } \\
\text { reading. Studies at the last minute. Memorizes information. } \\
\text { Reproduces ideas from source texts. }\end{array}$ \\
\hline Knowledge Learner & Excited by learning & $\begin{array}{l}\text { Focuses on the topic. Reads widely. Relates new ideas to previous } \\
\text { knowledge. Thinks analytically. Discusses the topic whenever } \\
\text { possible. }\end{array}$ \\
\hline
\end{tabular}




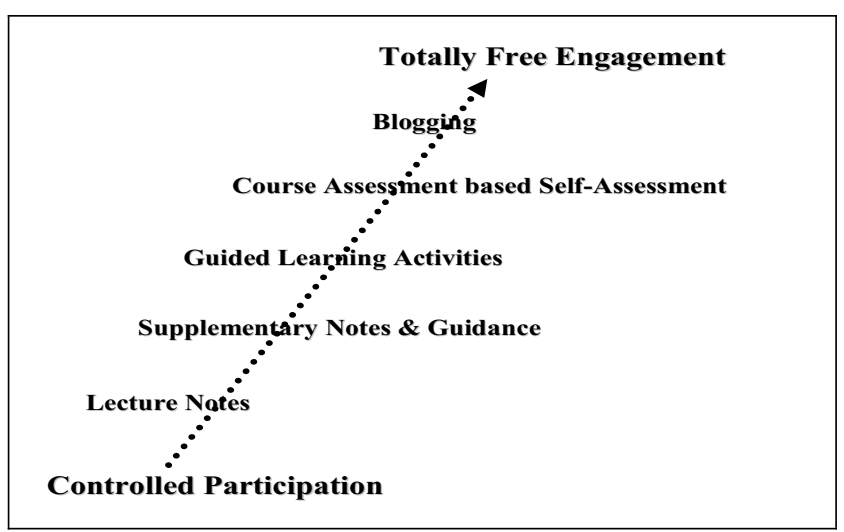

Figure 1. The Literature Online Programme Model

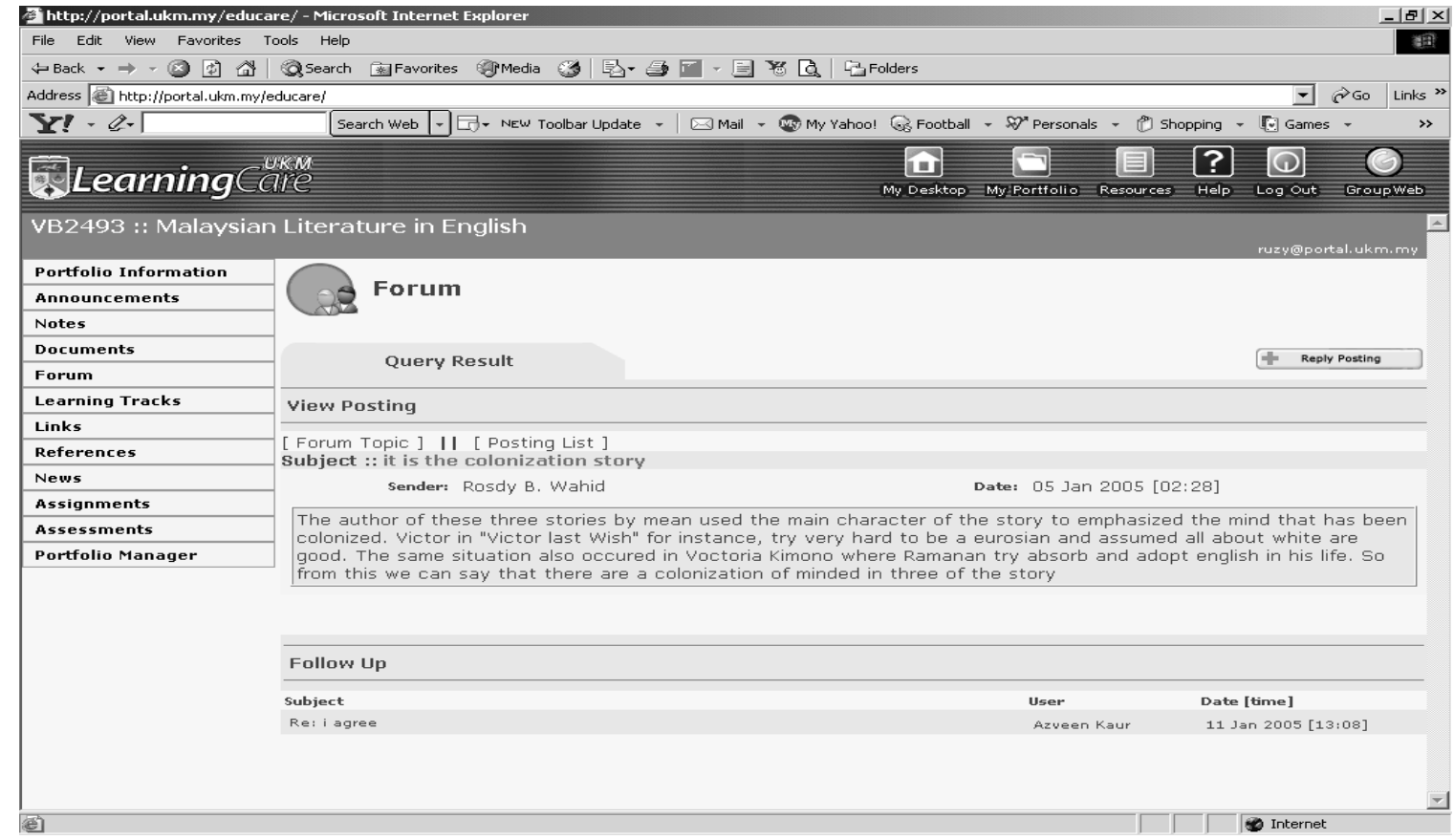

Figure 2. Screen Captures of Learner Engagements 